\title{
REFLEXÕES SOBRE HOMENS, MANGUEZAIS E CARANGUEJOS EM BRAGANÇA-PA
}

\author{
Luis Saraiva ${ }^{1}$ \\ Jéssica Corrêa ${ }^{2}$
}

\section{Introdução}

\begin{abstract}
Esta é que foi minha Sorbonne: a lama dos mangues do Recife, fervilhando de caranguejos e povoada de seres humanos feitos de carne de caranguejo, pensando e sentindo como caranguejo. Seres anfíbios - habitantes da terra e da água, meio homens e meio bichos. Alimentados na infância com caldo de caranguejo, este leite da lama. Seres humanos que se faziam assim irmãos de leite dos caranguejos. Que aprendiam a engatinhar e andar com os caranguejos da lama e que depois de terem bebido este leite de lama, de se terem enlambuzado com o caldo grosso da lama dos mangues, de se terem impregnado do seu cheiro de terra podre e de maresia, nunca mais se podiam libertar desta crosta de lama que os tornava tão parecidos com os caranguejos, seus irmãos, com as suas duras carapaças também lambuzadas de lama. (Castro, 2007: 13)
\end{abstract}

O homem e o mangue, o caranguejo e o caranguejeiro, distintas maneiras de apresentar relações, ou mais especificamente, socialidades (Ingold, 2015, 2000) que são construídas na interação entre humanos e não humanos. Contudo a partir de uma ineficiência de argumentos e ferramentas linguísticas frágeis para expressar em palavras o que nossos sentidos captam em relação ao contexto pesquisado, da riqueza de saberes e habilidades, que até é possível descrever de forma oral e escrita, mas que não conseguem dar conta da riqueza de detalhes presentes nas experimentações desses diferentes sujeitos em movimento.

Assim apresentamos o trabalho com caranguejos e caranguejeiros que aconteceu a partir do convívio com trabalhadores do mangue que residem na comunidade de Bacuriteua, na cidade de Bragança-Pará, localizada a aproximadamente $210 \mathrm{~km}$ da capital paraense. A pesquisa de campo foi realizada durante o ano de 2015 com caranguejeiros que fazem a captura do Caranguejo-Uçá (Ucides cordatus) nos $26 \mathrm{~km}$ de manguezal cortados pela PA-458, rodovia que dá acesso à praia de Ajuruteua.

Realizamos entrevistas abertas com um total de 15 caranguejeiros, com perguntas relacionadas ao cotidiano laboral no manguezal e de aspectos sobre mudanças percebidas a partir da construção da PA-458, foi possível ainda, acompanhar dois desses

\footnotetext{
${ }^{1}$ Universidade Federal do Pará, Brasil.

2 Universidade Federal do Pará, Brasil.
} 
trabalhadores em sua atividade de extração do caranguejo. Os caranguejeiros de um modo geral têm apelidos, mas preferimos identificar no trabalho o primeiro nome de cada um, com o consentimento deles.

O caranguejo tem um importante valor econômico na cidade e nessa perspectiva buscamos identificar e relacionar esse não humano a outros atores sociais como: políticos que discutem novas leis de proteção ao invertebrado, o cientista que pesquisa a espécie, e o caranguejeiro que obtém seus ganhos da extração e venda do animal. Investido de um valor social o caranguejo é pensado pelos humanos como um ser de fundamental importância ecológica e econômica, e com reflexos evidentes nas políticas humanas relacionadas ao ambiente e com interferências diretas no cotidiano dos profissionais do mangue (caranguejeiros).

Em aspectos gerais a atividade de captura do caranguejo é uma prática semelhante ao que autores como Diegues (2004), Maldonado (1993) e Ramalho (2015), identificam enquanto características da pesca artesanal em determinadas regiões. Tratase de uma atividade tradicional com dependência direta dos recursos naturais para sua existência material, efetivada a partir da utilização de técnicas e de tecnologias de trabalho artesanal, também caracterizadas por um modo de vida baseado na oralidade, determinando uma das formas de transmissão de saberes e fazeres.

Os caranguejeiros, que identificamos também como trabalhadores do mangue, realizam apenas a atividade de extração do caranguejo e apresentam as características identificadas anteriormente relacionadas à pesca artesanal. Esses profissionais moram em comunidades próximas ao local de extração de caranguejo e, na maioria das vezes, utilizam o ônibus ou a bicicleta para seguirem até a área de mangue que identificam como a mais apropriada à extração do invertebrado.

Em relação ao trabalho de extração do caranguejo, ressaltamos que existem políticas de preservação na região, direcionadas para o período de acasalamento da espécie, com definições anuais para o defeso ${ }^{3}$, no qual são veiculadas diversas propagandas que humanizam os animais e geralmente são acompanhadas de frases, tais como: "deixem o caranguejo namorar!".

\footnotetext{
${ }^{3} \mathrm{O}$ defeso é definido como o período de proibição da captura do caranguejo, e corresponde a fase de reprodução da espécie. Esse momento é definido por três semanas intercaladas entre os meses de janeiro a março. Sua regulamentação ocorre a partir da lei n ${ }^{\circ} 11.959$, de 29 de junho de 2009.
} 
Outras questões foram surgindo no decorrer do desenvolvimento da pesquisa, principalmente relacionadas às questões ambientais, que mais diretamente proporcionaram uma reflexão sobre o tema da socialidade, pois assim como os caranguejos e os manguezais se adequam constantemente as mudanças que surgem no ambiente, os caranguejeiros fazem um movimento semelhante para adequação à realidade encontrada que possibilite um bom desempenho para a captura, o transporte e a comercialização do animal.

De acordo com Reis (2007) a vida econômica, social e cultural dos grupos humanos moradores das proximidades das regiões de manguezal está intimamente ligada à flora e à fauna do manguezal, aos ciclos lunares, sazonais e de maré, aos períodos de reprodução de peixes, caranguejos e outras espécies. O que também é destacado por Vannucci (2002), quando a autora analisa que a maioria dos animais possuem ritmos fisiológicos que correspondem aos ciclos lunares, sazonais ou de monção. Assim, como já destacado anteriormente, tanto caranguejos, quanto caranguejeiros e o próprio espaço do manguezal, se adequam às mudanças ambientais em uma estrutura cíclica de relações socioambientais que resultam em constantes adaptações.

Nessa perspectiva, são os aspectos ambientais que definem a atividade econômica dos caranguejeiros, pois só é possível capturar o caranguejo se existir a presença do animal em tamanho adequado para a comercialização, levando em consideração que esse aspecto (o tamanho) já sofreu bastante influência com a intensificação da atividade. Ressaltamos ainda, que o desenvolvimento da espécie só é possível se o habitat estiver em condições adequadas para tal, existindo assim relações que precisam ser compreendidas. Portanto, estabelecer uma reflexão sobre as dinâmicas socialidade entre caranguejos e caranguejeiros nos impulsiona, em um primeiro momento, para a sensibilização do nosso olhar em direção ao contexto dos manguezais.

\section{Os lugares nos quais se movimentam homens e caranguejos: os manguezais}

Os manguezais são áreas legalmente protegidas de acordo com a lei $\mathrm{n}^{\circ} 12.651$, de 25 de maio de 2012, conforme consta no Art. $4^{\circ}$ que define as áreas de Preservação Permanente, parágrafo VII, pois os manguezais são áreas de preservação em toda a sua extensão. Em um contexto mais amplo, para todas as regiões com presença de 
manguezais, percebe-se que durante os períodos de colonização muito prejuízos foram causados a esses ecossistemas considerados improdutivos, como destaca Vannucci (2002: 35) 'tudo aconteceu para 'melhor uso' aquelas terras 'más' (...). Tudo aconteceu porque nenhum estrangeiro tinha tentado realmente entender o ecossistema manguezal". A autora destaca ainda que somente a partir de 1931 foram elaboradas as primeiras concepções que demonstravam as particularidades fundamentais dos manguezais, definindo essas áreas como vloedboschen (florestas alagadas).

A importância dos manguezais para a realização de pesquisas científicas também é bastante evidente na região estudada no presente artigo, tanto em relação aos estudos referentes aos caranguejos, até os níveis de carbono presentes nos mangues. Entretanto, mesmo sabendo que as áreas de mangue são protegidas legalmente, e que a região de manguezal de Bragança-PA tem forte presença de pesquisadores, durante as entrevistas com os caranguejeiros eles destacaram a falta de fiscalização, principalmente para questões relacionadas ao desmatamento no meio da floresta de mangue, além da retirada ilegal de crustáceos nos períodos do defeso, e da grande quantidade de animais que são levados para comercialização em outras regiões.

Com relação aos impactos ambientais presentes nas áreas de manguezais aqui estudadas, destacamos a construção da PA-458 como um fator importante para compreender as dinâmicas que intensificaram, por exemplo, a predação do caranguejo. A rodovia liga a cidade de Bragança a atual praia de Ajuruteua, que antes da estrada, de acordo com os moradores da Vila do Bonifácio, era uma fazenda chamada Campo do Meio. Evidenciamos essa questão, pois de acordo com os atores sociais envolvidos na pesquisa, a estrada foi construída com o objetivo de facilitar o acesso dos moradores daquelas regiões de praia ao espaço urbanizado da cidade, o que antes era realizado apenas por embarcações de pequeno porte. A construção desta rodovia estadual foi iniciada no final de 1970 e concluída no ano de 1983, a ocupação da praia aconteceu rapidamente, com maior intensidade em 1987 (Maneschy, 1995). De acordo com Pereira et al (2001: 20) a PA-458 "facilitou/possibilitou a expansão urbana e incentivou o inicio do turismo na região", nesse sentido, o turismo também foi um importante elemento motivador para a construção da rodovia. 
Trata-se de $26 \mathrm{~km}$ de extensão de mangue que foram cortados com a construção da estrada, deixando um rastro de problemas ambientais, como a alteração da drenagem natural de parte do ecossistema que agora está dividido. Depois da construção da estrada, ocorreu um significativo aumento da quantidade de tiradores de caranguejo e, também, do número de atropelamentos dessa e de outras espécies, principalmente no período das férias e durante "a andada do caranguejo", momento em que saem das galerias para a efetivação do acasalamento (Pereira, 2006).

A estrada é um elemento presente na fala dos trabalhadores do mangue, enquanto um marco histórico de extrema importância para o seu trabalho, em seus aspectos positivos e negativos. Nas falas é possível acompanhar contextos extremamente divergentes do antes e do depois da estrada. A própria temporalidade é modificada, como fica marcante na percepção dos caranguejeiros que se deslocam cotidianamente pela estrada para chegar ao seu espaço de trabalho no manguezal.

Foi possível entender melhor essa dinâmica ao acompanharmos o senhor Benedito, que gosta de ser chamado de Bené, que no auge dos seus 30 anos de profissão lembra de um tempo em que se deslocava para o manguezal de canoa. Segundo seu Bené "a estrada ajudou muito, logo no começo a gente saía da estrada e já entrava no mangal pegando caranguejo, hoje não é bem assim, mas também com tanta gente pegando caranguejo ele se afasta mais".

Seu Bené nos apresenta questões relacionadas à construção da estrada, falando da facilidade atual de deslocamento para os locais propícios à captura do caranguejo, em contrapartida, apresenta as dificuldades da atividade nos dias atuais (referente ao período da pesquisa), a exemplo da diminuição tanto do tamanho como da quantidade do caranguejo e o aumento do número de caranguejeiros. O beneficio da estrada apresentado por seu Bené esconde várias desvantagens, pois os caranguejeiros já não encontram a mesma fartura de caranguejos, e têm que trabalhar dobrado para conseguir a metade do que conseguiam antes da construção da estrada. 


\section{Os trabalhadores do mangue}

Nossa pesquisa iniciou na comunidade do Bacuriteua a partir de informações de moradores locais sobre os profissionais do mangue mais antigos. No primeiro contato com esses profissionais nos foi relatado os problemas ambientais que envolviam a construção da PA-458, os questionamentos relacionados as definições do período mais adequado do defeso, desmatamentos nas áreas de manguezais. Solicitamos após cada entrevista a indicação de outros caranguejeiros que também tivessem acompanhado o antes e o depois da construção da estrada e que pudessem falar sobre as demais questões. Em um segundo momento, nos permitimos percorrer a rodovia e observar a vida acontecendo, atentos para as dinâmicas envolvendo humanos, animais e o manguezal. Observamos alunos efetivando pesquisas, animais atropelados, caranguejeiros se organizando para retornar em suas bicicletas ou esperando o ônibus passar, áreas com grandes árvores, outras com apenas pequenos arbustos.

Ao retornar para Bragança, oferecemos uma carona para um dos caranguejeiros que já estava à espera do ônibus, senhor Francisco, com seus 25 anos de profissão, morador da comunidade do Bacuriteua, nos disse que iniciou na profissão desde bem jovem quando "arrumou família e precisou sustentar os filhos" ${ }^{4}$. Ele relatou que quase todo dia segue o mesmo ritmo, acordando as 5 h30 para organizar seus materiais de trabalho e, a partir daí segue para as margens da estrada para embarcar em um ônibus e se deslocar aos locais de captura do caranguejo, por volta das $12 \mathrm{~h}$ ou $13 \mathrm{~h}$ (dependendo do dia) já está as margens da estrada com suas 8 a 10 cambadas $^{5}$, à espera do ônibus para retornar.

Os caranguejeiros convivem em proximidade com os manguezais e caranguejos, nesse sentido, conhecem o ritmo dos animais com muita propriedade, como no caso do seu Francisco quando este faz algumas considerações relacionadas ao período do defeso.

\footnotetext{
4 Anotação em diário de campo, 20 de julho 2015.

${ }^{5}$ As cambadas correspondem aos animais capturados e separados para a venda, pois na cidade eles são vendidos em agrupamentos com 14 caranguejos.
} 
Eu não acho correto o período que eles dizem que é o defeso, acho que depois da andada que era pra parar de pegar, pois o caranguejo fica com o casco mole e a gente tem que usar o gancho porque ele tá mais fundo e muitas vezes quebra o casco. (...) ainda tem gente que sente que furou o casco com o caranguejo ainda no buraco e não tira de lá, naquele buraco não vai entrar nenhum outro caranguejo, aquilo fica podre, muito fedorento. (Senhor Francisco, entrevista realizada em junho 2015.)

Ao questionar o período do defeso, senhor Francisco, nos faz questionar o distanciamento apresentado pelo profissional do mangue em relação as decisões políticas para o período definido do defeso da espécie. Suas colocações são pertinentes, pois o momento após a "andada" (acasalamento) é evidenciado pela troca de carapaça (ecdise), influenciada pela ciclos lunares e de marés. De acordo com Nordi (1994) os órgãos ambientais responsáveis pelo manejo da espécie $U$. Cordatus desconsideram os conhecimentos sobre os animais e o espaço de coleta dos trabalhadores do mangue, fator preponderante para a baixa eficiência das normas de regulamentação.

Conforme apresentado na entrevista com o senhor Francisco, em algumas situações os trabalhadores do mangue precisam fazer uso do gancho (vara de madeira com a ponta de ferro dobrada em formato circular - figura 1) que é usado nas galerias em que o braço do caranguejeiro não consegue alcançar o animal. No entanto, a utilização desse utensilio traz alguns problemas, como por exemplo, o gancho fura com facilidade o casco do animal (figura 2). Ele sabe que a utilização do gancho não é a melhor solução, mas é necessária, caso contrário a quantidade de caranguejos capturados será pequena. 

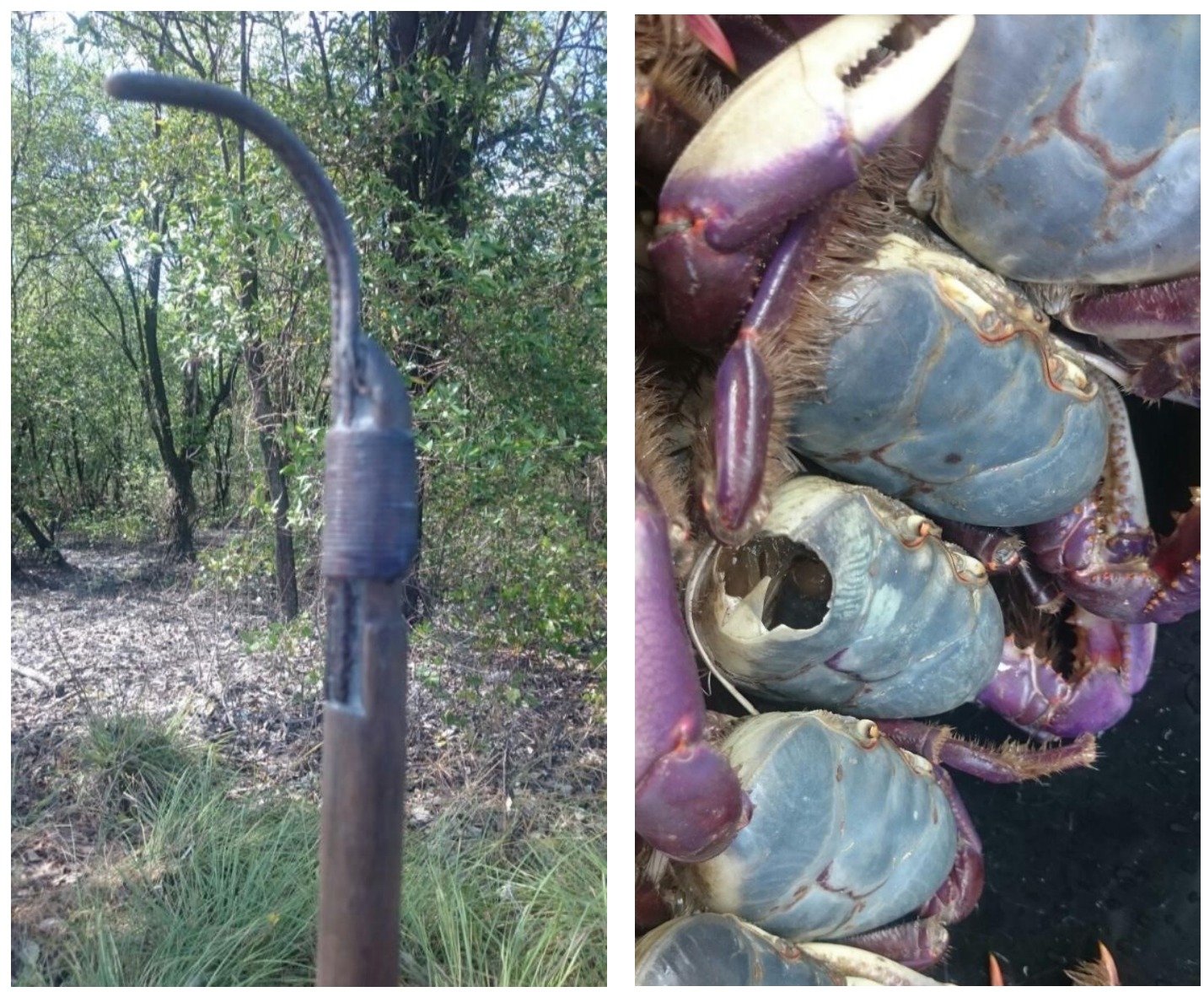

Figura 1: Gancho utilizado para capturar caranguejos em profundidades que o braço não alcança. Figura 2: Caranguejos logo após a captura com destaque no casco furado pelo gancho.

Fonte: Arquivo pessoal.

Ele nos informou, ainda, que geralmente quando a carapaça do animal se quebra ele morre e assim terá que ser descartado, pois para a comercialização só vale o animal vivo. Seu Francisco relata a respeito da falta de preocupação de muitos profissionais do mangue com uma dinâmica de relação com o ambiente mais ética. Nessa perspectiva é possível pensar na existência ou não da harmonia entre os diferentes atores que compartilham o espaço dos manguezais, e nessa convivência, essa relação nem sempre é vantajosa para os animais e o mangue, mas também não será para os humanos, pois a utilização compensatória de um recurso natural somente será possível por um período mais prolongado se houver uma utilização sustentável desses recursos. 


\section{O caranguejo}

Os caranguejos são atores importantes nos contextos aqui apresentados, seja no âmbito comercial e/ou científico, e nesse sentido a noção de mediação apresentada por Latour (2001) enquanto uma ponte ligando diferentes atores que atuam em um mesmo contexto faz-se necessário para a reflexão. Nesse sentido, o manguezal desempenha uma função de mediação, pois representa o elo da interação entre humanos caranguejeiros e caranguejos, nos contextos de captura para a comercialização, ou ainda humanos biólogos e caranguejos no momento em que estes coletam os animais para estudos em laboratório.

Em entrevista com Marcus Fernandes, biólogo, professor e pesquisador na Universidade Federal do Pará, coordenador do Laboratório de Ecologia de Manguezal (LAMA), e que realiza pesquisas há mais de 10 anos nas áreas de manguezal em Bragança-PA, ressalta que no momento em que a estrada foi construída, o caranguejo não tinha a importância científica que tem hoje, pois o mesmo atualmente é bastante pesquisado, inclusive pelo próprio Fernandes (2003), com um conjunto de importantes contribuições científicas sobre os manguezais da costa norte brasileira, e faz parte dos temas que estão sob os holofotes científicos de áreas como a Biologia, mas também em áreas como a Sociologia, a exemplo de trabalhos como Oliveira (2013) e Oliveira e Maneschy (2014).

Apesar do caranguejo não ter importância científica na região antes da construção da estrada, esse animal já apresentava valor para os caranguejeiros, que, por sua vez, já conheciam seus hábitos e características. O que percebemos é o desencontro entre os saberes tradicionais e os conhecimentos científicos, como no caso dos questionamentos dos caranguejeiros em relação à discordância ao período do defeso, como apresentado anteriormente e também em relação ao tempo que o caranguejo leva para chegar a fase adulta e o período de seu desenvolvimento de modo geral. Nessa perspectiva Alves e Nishida (2002), que pesquisaram o ciclo de vida do caranguejo-uça a partir da percepção ambiental dos caranguejeiros em diálogo com as técnicas cientificas de observação e análise, identificaram que a prática cotidiana dos caranguejeiros tem reflexo numa percepção elaborada de fatores físicos que estão relacionados às etapas do ciclo de vida desse crustáceo, a ecdise (troca de carapaça), por exemplo, é associada ao movimentos das marés que por sua vez está diretamente 
relacionada aos ciclos lunares. Nesse sentido, estudos de etnomanejo que associam conhecimentos tradicionais aos saberes científicos possibilitam o planejamento de políticas de uso sustentável dos recursos naturais em diálogo aberto e democrático com as populações locais.

Cabe nesse momento dialogar com questões discutidas por Latour (2001, 2004), especialmente quando o autor chama a atenção para a relação com os não humanos, e a forma como nos relacionamos com esses sujeitos. Nesse caso, não diz respeito apenas à maneira, controladora, com que lidamos com os animais, mas é preciso observar como os caranguejeiros são desvalorizados socialmente, o que gera em alguns um sentimento de inferioridade, que auxilia para a certeza de não querer um filho seguindo seus exemplos profissionais.

Atentar para a valorização dos animais é identificar inicialmente a forma como eles se enquadram na realidade cotidiana, e seu valor social, pois seguindo essa divisão entre humanos e animais, o caranguejo possui um valor social que é pensado por humanos, e têm impactos em políticas humanas. Entretanto, esse conjunto de relações que compõem a dimensão política da natureza (Latour, 2004), terminam por ter impactos negativos, para caranguejos, caranguejeiros e para o manguezal, como no caso da estrada PA-458 e os impactos ambientais gerados a partir da sua construção.

Compreender a capacidade dos animais em relacionar-se com o ambiente, requer uma atenção minuciosa ao comportamento destes, e ao modo como as mudanças ambientais impõem adaptações, mais rapidamente até que aos humanos (Ingold, 2015). Nesse aspecto podemos considerar as mudanças de comportamento e a reorganização feita pelos caranguejos no seu habitat, a exemplo disso consideramos o que nos foi pontuado pelos caranguejeiros enquanto dificuldade encontrada por estes durante o trabalho de captura, pois nos últimos anos os caranguejos habitam galerias mais profundas o que é, segundo os caranguejeiros, um indicativo de que eles estão buscando formas de se proteger da predação humana. Assim, trata-se de uma rede de relações, pois as transformações humanas provocarão consequentemente uma readequação não humana e vice-versa.

Para o entendimento da relação entre humanos, animais e ambiente, o termo socialidade (Ingold, 2015, 1995, 1991) nos auxilia na compreensão das relações existentes entre esses atores, para além de uma simples interação, mas enquanto um conjunto de simbologias que surgem nas relações estabelecidas de forma constante e 
integrada entre uma ecologia simbólica e ecossistêmica. Essa socialidade caracteriza uma relação que apresenta aspectos de cooperação e interação entre humanos e humanos, humanos e animais/ambiente. Ingold (1991) vai além ao falar que para alcançar os aspectos identificados é necessário desenvolver habilidades especificas para cada contexto, que permitam aos humanos estabelecer uma socialidade com animais, ambiente e/ou outros humanos.

Ancorados nas perspectivas de socialidade, pensar no contexto dos manguezais é perceber nos humanos caranguejeiros um sujeito que desenvolveu as habilidades necessárias para estabelecer uma socialidade com os caranguejos satisfatória para ambos, de todo modo percebermos a partir das entrevistas que questões de manejo sustentável não estão sendo efetivadas por todos os profissionais do mangue, em que saberes relacionados aos ciclos lunares, de maré e aspectos comportamentais da espécie, repassados oralmente, estão distanciados da utilização sustentável dos recursos naturais.

\section{"Ele mina": reflexões sobre a relação entre caranguejeiros e caranguejos}

O título do presente tópico faz referência a ideia de um fluxo incessante de caranguejos, em outras palavras ele mina. O termo surgiu na entrevista feita com seu Antônio, o qual já está completando 35 anos como tirador de caranguejo, e não deixa de questionar o olhar de pesquisadores que já passaram pelos locais que o mesmo trabalha, pois segundo ele, com relação ao tempo de crescimento do caranguejo, como é possível explicar que no buraco em que capturamos um animal em um determinado dia, no dia seguinte, no mesmo lugar já terá outro, numa clara alusão a ideia de que existem elementos relacionados ao desenvolvimento do caranguejo que não podem ser explicados, simplesmente acontecem de forma sobrenatural.

É claro que o caranguejo mina, é claro que ele mina, vocês, então, não vê?! Você vai um dia e tira caranguejo em um buraco, aí no outro dia você volta e tem outro do mesmo tamanho, no mesmo buraco. Como o cientista explica isso? Dizer que o caranguejo cresce de sete em sete anos é mentira deles, você tirar hoje o caranguejo, amanhã você vai no mesmo buraco e já tem outro. Em algumas partes o caranguejo já tem acabado, principalmente devido eles derrubar o mangal e colocar rede também no meio do mangal. (...) com isso fica com mais dificuldade por causa que a gente tem que buscar um novo ponto pra pegar o caranguejo e mais longe. (Seu Antônio, entrevista realizada em setembro de 2015). 
O que foi possível observar é que os conhecimentos dos caranguejeiros, principalmente relacionados aos aspectos físicos e ambientais que influenciam os comportamentos dos animais são, na maioria das vezes, ignorados pelas produções cientificas na região, a exemplo de Glaser, et all (2005) e Saint-Paul e Schneider (2010). Tal situação converge para alguns problemas que refletem nas políticas ligadas ao controle da captura do caranguejo. Nesse jogo de interesses diversificados é possível perceber o quanto os resultados dessa rede de relações entre humanos e não humanos esbarra em interesses políticos diversos.

$\mathrm{Na}$ entrevista seu Antônio faz referência ao incômodo que lhe causa as respostas apresentadas por pesquisadores em relação ao tempo de maturação do caranguejo, pois para ele sete anos é um tempo demasiadamente longo, que não corresponde ao que ele observa cotidianamente, seu questionamento também nos faz refletir sobre a maneira como as respostas são construídas e apresentadas ao público não acadêmico. Ele trabalha nessa atividade há mais de trinta anos, convive quase todos os dias com lamas nos pés, próximo aos caranguejos, portanto conhece os crustáceos de perto, por esses e por outros fatores justifica-se a resistência em aceitar que alguém em poucos meses ou dias, cerquem um pequeno espaço do mangue e, a partir da observação desse espaço isolado, definam quanto tempo o caranguejo leva para alcançar a maturação ${ }^{6}$.

Seu Antônio identifica os problemas socioambientais existentes no contexto dos manguezais, e reclama da falta de fiscalização e da ausência de cobranças mais sérias no cumprimento das leis. No decorrer da conversa o caranguejeiro apresenta problemas relacionados ao desmatamento observados por ele durante a atividade de captura do animal, ele trabalha sozinho e nos fala que já presenciou pessoas no meio do manguezal cortando as árvores de mangue, seu Antônio considera essa atitude muito errada, mas não se sente seguro para denunciar.

Agora não, mas antes eu saía do mangal com 10 ou 12 cambadas, mas agora eu só consigo sair com 6 ou 7 cambadas. O trabalho do mangal é um trabalho que a cada dia a gente vai perdendo as nossas forças, sem falar que a gente corre muito risco (...). A cada ano a população de tirador de caranguejo vai aumentando e ele vai diminuído (quantidade), tem partes que a gente só encontra aqueles bem miúdo. (Seu Antônio, entrevista realizada em setembro de 2015)

\footnotetext{
${ }^{6} \mathrm{O}$ experimento apresentado faz parte de um conjunto de pesquisas realizadas nas áreas de manguezal da RESEX, que ocorreram há dez anos atrás, a partir de um projeto de colaboração entre o Brasil e a Alemanha, sediado no campus da UFPA-Bragança. Sobre o conjunto de pesquisas realizadas nas áreas de manguezal na região bragantina conferir Glaser, et all 2005, Saint-Paul e Schneider 2010.
} 
Capturar uma quantidade suficiente para vender e garantir, assim, a renda familiar é atualmente o grande desafio dos caranguejeiros, sem falar dos riscos físicos que seu Antônio apresenta, além da possibilidade de furar os pés ou as mãos, ou ainda, de ser mordido por animais peçonhentos. Algumas das dificuldades apresentadas por seu Antônio já haviam sido sistematizadas por autores como Oliveira e Maneschy (2014), como: a diminuição no tamanho do caranguejo; maior profundidade para a coleta do animal, forçando o uso do gancho; e maiores distâncias percorridas para encontrar locais com quantidade de caranguejo satisfatória.

A imagem de como era a região de mangue antes da estrada existir é algo que podemos tentar mapear apenas a partir dos relatos dos caranguejeiros, que utilizam continuamente a estrada, mas que em alguns casos já acompanhavam seus pais no tempo em que a estrada não existia. São os caminhos da estrada e antes dela, mas são também os caminhos da memória, que "são resultados de sistemas dinâmicos de organização e apenas existem na medida em que a organização os mantém e os reconstitui" (Le Goff, 1996: 424).

A memória do que foi a região ajuda a reconstruir o que são hoje os espaços nos quais os caranguejeiros frequentam, e é através do ato de narrar, que surgem os fios que unem esses sujeitos humanos aos não humanos. Seus relatos apresentam não só outros trajetos, mas também, outras temporalidades, como fica marcante na narrativa de seu Carlos, morador da comunidade de Bacuriteua, que exerce a profissão de caranguejeiro a 35 anos e começou na atividade ainda na infância.

\footnotetext{
Naquele tempo era muita dificuldade, pra tirar o caranguejo pois era só de canoa, e a tiração do caranguejo era dois dias. Nesse tempo em que não havia a estrada era mais tempo para tirar e chegar com o caranguejo na cidade. Agora não, você sai de manhã e a tarde você já tirou, já trouxe, e já vendeu e já tá com o dinheiro na mão. (Entrevista com o senhor Carlos, 2015)
}

As mudanças descritas pelo senhor Carlos são mais profundas do que parece a um olhar apressado. A temporalidade existente antes da estrada ditava um ritmo de coleta, de transporte e de venda do caranguejo muito diferente do que passou a ser depois que a estrada foi construída, como também trouxe consequências que nas palavras do próprio Carlos, apresentam aspectos positivos, acompanhados de aspectos negativos. 
Se por um lado a estrada possibilitou a facilidade para o escoamento da produção de caranguejo, a dificuldade atual é a de conseguir a mesma quantidade de outrora, pois fica evidente nos relatos a diminuição desse animal que foi muito abundante no passado. Durante a entrevista com outro caranguejeiro, seu Adão, que reside na comunidade do Bacuriteua e trabalha na coleta do caranguejo há mais de 22 anos, fica evidente que logo após a construção da PA-458, o caranguejeiro coletava o caranguejo a poucos metros de distância da estrada, recentemente nos mesmos locais de coleta é preciso andar bastante manguezal adentro para conseguir coletar o invertebrado, o que dificulta o trabalho, pois após recolher uma quantidade suficiente de animais para a venda é necessário trazê-los até a estrada.

Os caranguejeiros têm uma rotina de trabalho árdua e enfrentam dificuldades particulares, especialmente àquelas ligadas ao modo como tal atividade exige do caranguejeiro certas habilidades no exercício de suas tarefas. Acompanhando seu Adão, em um dia de trabalho foi possível perceber que ele acorda às $5 \mathrm{~h}$ da madrugada, prepara seus materiais de trabalho e segue de ônibus até um certo ponto da estrada, para depois entrar no manguezal. Seu suprimento alimentar é composto basicamente de farinha de mandioca com carne ou peixe salgados, mas em alguns momentos somente a farinha de mandioca será utilizada para saciar sua fome, por volta das 10 horas da manhã. Após a refeição o senhor só voltará a se alimentar com a conclusão de todas as demais etapas do seu trabalho, algo por volta das 14 ou 15 horas da tarde.

Então a diferença, na época era poucos caranguejeiro, mas hoje a população (humana) cresceu mil por cento, porque assim que abriu essa estrada aqui, você não arrastava o pé da pista pra tirar o caranguejo, o caranguejo estava na beira da estrada, e era só caranguejo graúdo, hoje você anda 5 a $6 \mathrm{~km}$ pra dentro do mangal, entendeu, tá lá o mesmo mangal, tá lá o mesmo onde eu cansei de fazer na época, 15 a 20 cambadas, na época se eu entrasse, é, 8 horas como hoje eu entro, quando era o máximo 10 horas, 11 horas, eu tava com 20 cambadas, porque em todo lugar que você chegava o caranguejo estava se mostrando. Todo buraco que você metesse a mão tinha, entendeu? (Entrevista com o senhor Adão, 2015)

As mudanças descritas por Adão foram estudadas por Oliveira e Maneschy (2014), e estes argumentam que as mesmas são frutos das transformações ocorridas no sistema de coleta do caranguejo voltado ao consumo e à venda do excedente, para um sistema mercantil totalmente voltado para suprir as demandas de um mercado sempre ávido por uma produção maior, que possibilite dar conta das várias demandas internas e externas. 
Os trabalhadores do mangue que acompanhamos no decorrer da pesquisa realizam a extração de caranguejo na Reserva Extrativista Caeté-Taperaçu (RESEX), fator importante para refletir sobre aspectos pontuados na pesquisa, tais como, os impactos ambientais observados pelos caranguejeiros nas áreas de manguezais, pois trata-se de um espaço que deveria ter uma fiscalização mais frequente para o uso sustentável dos recursos oriundos do mangue, que sofrem com um certo descaso.

$\mathrm{Na}$ pesquisa realizada por Queiroz e Peralta (2006) eles identificam que a maioria dos usuários de uma Resex compreendiam a reserva enquanto um meio para o controle do uso dos recursos por agentes externos, no sentido de impedir que a atividade de coleta fosse realizada em época de defeso, que no caso dos caranguejos é caracterizado pela andada para o acasalamento, nos meses de janeiro a março.

Caminhando atento por entre as raízes do mangue ao identificar as cavidades, o caranguejeiro coloca meio braço dentro da toca e, dependendo da profundidade, coloca todo o restante. Em alguns momentos, para quem observa a situação, a lama transformase em tapete aconchegante no qual todo o corpo do tirador de caranguejo irá se debruçar para facilitar o seu trabalho de captura. Neste sentido, as técnicas do corpo (Mauss, 2009) tornam-se os mecanismos mais eficazes para essa atividade, o corpo é o instrumento eficiente para estabelecer uma relação mais dinâmica com o animal, pois quando o trabalhador do mangue consegue tocar o caranguejo com os dedos, sentindoo, tem condições de perceber se o tamanho está ideal para captura ou não.

Nessa relação entre humanos caranguejeiros e não humanos caranguejos, a noção de técnicas corporais de Mauss (2009) pode ser ampliada para pensar esse uso do corpo nas relações construídas socialmente no contexto especifico dos manguezais. $\mathrm{O}$ exemplo disso pode ser pensado na forma como os caranguejeiros utilizam instrumentos para ampliar suas capacidades corporais, como o gancho (figura 1), sapatos adaptados, luvas e outros apetrechos, mas, por sua vez, os caranguejos também usam seu corpo para fugir dos predadores, como quando precisam largar suas patas maiores na tentativa de conseguir fugir, se a fuga for bem sucedida, posteriormente a pata nascerá novamente. As transformações sociais e culturais da utilização do corpo por ambos (humanos e não humanos) em aspectos temporais e espaciais específicos, têm suas significações construídas e redefinidas social e historicamente. 
Refletir sobre humanos e não humanos no contexto dos manguezais nos aproxima de discussões socioambientais e políticas, que por sua vez esbarram em questões de organização social, mas também tem reflexo no cotidiano de caranguejeiros que retiram seus ganhos financeiros da coleta do caranguejo, este último por sua vez sofreu nas últimas décadas mudanças, consequência da predação humanas que se intensificou, por conta da demanda sempre crescente de um mercado de compra e venda de carne de caranguejo.

\section{Considerações finais}

O caranguejo e os caranguejeiros estão no foco de discussões que envolvem o planejamento político para a preservação das áreas de manguezal e de sua fauna e flora. Entretanto, como destacado por alguns caranguejeiros já aqui referidos, esse planejamento e controle não é eficiente, pois a cobrança não ocorre de forma ampla e satisfatória, com fiscalização, acompanhamento e orientação adequadas.

Humanos (caranguejeiros) e não humanos (caranguejos) estabelecem entre si um conjunto de (re)significações de aspectos ambientais, como no caso dos humanos caranguejeiros que precisam lidar com a escassez de caranguejos, ou destes últimos que precisam se adaptar a mudanças climáticas, ou ainda com a derrubada de áreas de florestas de mangue. O caranguejo tornou-se ao longo dos anos, após a construção da PA-458, o foco de pesquisas cientificas e consequentemente de ações politicas que se intensificaram nesse período e se mantém até os dias atuais. O presente trabalho não está distante desse grupo de interessados no mangue e em seus sujeitos, mas nosso objetivo foi acompanhar aqueles que mais próximos estão dos caranguejos, os trabalhadores do mangue, homens com muitas histórias para contar sobre suas vivências nas áreas de manguezais em sua faina diária extraindo caranguejos.

Considerando que a estrada construída na década de 70, foi um marco sóciohistórico para o contexto do manguezal, podemos nos perguntar para quem o caranguejo tinha importância no momento anterior a PA-458. O questionamento é simples de responder, mas precisa de uma reflexão mais detalhada e atenta sobre as relações entre caranguejos e caranguejeiros. Compreendemos, a partir dos relatos dos trabalhadores do mangue, que esses sempre mantiveram uma íntima relação de manejo e de conservação, com e sobre esses atores não humanos, e mesmo no momento anterior a estrada, em que, nem cientistas e nem políticos, estavam envolvidos e preocupados com os 
caranguejos, os caranguejeiros já mantinham uma tradição de contato com estes, pois serviam como uma das principais fontes de alimento para esses profissionais e suas famílias.

Em uma extensa linha de manguezal foi possível encontrar relações de interpendência que remontam a um passado distante em que esses homens do mangue criados, como diz Josué de Castro, com o leite do caranguejo, conviveram de forma harmônica com um ecossistema que hoje apresenta sinais de mudanças radicais. Um atual contexto que apresenta dificuldades a serem enfrentadas tantos por homens como por caranguejos, e nesse sentido clássicos da antropologia como Evans-Pritchard (1999) em seu trabalho sobre os Nuer, e na relação desse povo nilota com o gado, nos inspira a pensar nessa relação de interdependência entre homens e animais, em um tempo ecológico particularmente compreendido e compartilhado no espaço dos manguezais.

\section{Referências}

ALVES, Rômulo Romeu da Nóbrega e NISHIDA, Alberto Kioharu. A ecdise do caranguejouça, Ucides Cordatus L. (Decapoda, Brachyura) na visão dos caranguejeiros. Rev. Interciência, vol 27, n. 3 / Caracas, mar. 2002.

CASTRO, Josué de. Homens e Caranguejos. Rio de Janeiro: Civilização Brasileira, 2007.

DIEGUES, Antonio Carlos. A pesca construindo sociedades. São Paulo, Nupaub-USP, 2004. - Etnoconservação da natureza: enfoques alternativos. In: Diegues, A.C. (Org.) Etnoconservação: novos rumos para a proteção da natureza nos trópicos. São Paulo: HUCITEC/NUPAUB, 2000, p. 1-46. Pescadores, camponeses e trabalhadores do mar. São Paulo, Ática, 1983.

EVANS-PRITCHARD. E. E. Os Nuer. São Paulo: Editora Perspectiva, 1999.

FERNANDES, Marcus E. B. Os Manguezais da costa norte brasileira, Vol. II. São Luis: Fundação Rio Bacanga, 2003.

GADDIS, John Lewis. Paisagens da História. Como os historiadores mapeiam o passado. Rio de Janeiro: Editora Campus, 2003.

GLASER, Marion, CABRAL, Neila e RIBEIRO, Adagenor (orgs). Gente, ambiente e pesquisa: manejo transdisciplinar no manguezal. Belém: NUMA/UFPA, 2005.

INGOLD, Tim. Estar vivo: ensaios sobre movimento, conhecimento e descrição. Petrópolis, RJ: Vozes, 2015.

"Caminhando com dragões: em direção ao lado selvagem" In Steil, Carlos Alberto e Carvalho, Isabel Cristina de Moura (orgs.) Cultura, Percepção e ambiente. Diálogos com Tim Ingold. São Paulo, Editora Terceiro Nome, 2012.

Routledge, 2000.

The perception of the environment: essays on livelihood, dwelling and skill. Londres:

. Humanidade e animalidade. In: Revista Brasileira de Ciências Sociais. São Paulo: ANPOCS, v. 10, n. 28, 1995.

Becoming Persons: consciousness and sociality in human evolution. Cultural Dynamics. 4 (3): 1991.

LATOUR, Bruno. A esperança de Pandora. Ensaios sobre a realidade dos estudos científicos. Bauru, SP, EDUSC, 2001.

. Políticas da natureza. Como fazer ciência na democracia. Bauru, SP, EDUSC, 2004. 
LE GOFF, Jaques. História e memória. Campinas: Editora da UNICAMP, 1996.

MALDONADO, Simone. Pescadores do mar. São Paulo, Ática, 1986.

Mestres e Mares: espaço e indivisão social na pesca marítima. São Paulo:

Annablume, 1993.

MANESCHY, Maria Cristina. Ajuruteua, uma comunidade pesqueira ameaçada. Belém: Editora da UFPA, 1995.

MAUSS, Marcel (2009). As técnicas do corpo, in AA.VV. Corpo, colecção arte e sociedade (Dir. João Valente Aguiar), n. ${ }^{\circ}$ 1, Lisboa: Apenas Livros; Instituto de Sociologia da Faculdade de Letras da Faculdade do Porto, pp. 3-24.

NORDI, Nivaldo. A captura do caranguejo-uça (Ucides cordatus) durante o evento reprodutivo da especie: o ponto de vista dos caranguejeiros. Revista Nordestina de Biologia 9: 41-47.

OLIVEIRA, Marcelo do Vale; MANESCHY, Maria Cristina Alves. "Territórios e territorialidades no extrativismo de caranguejos em Pontinha de Bacuriteua, Bragança, Pará" In Boletim do Museu Paraense Emilio Goeldi Ciências Humanas. Vol. 9, n. 1, Belém, 2014.

OLIVEIRA, Marcelo do Vale. Trabalho e territorialidade no extrativismo de caranguejos em Pontinha de Bacuriteua, Bragança-Pará. Dissertação de Mestrado. Bragança: UFPA, 2013.

PEREIRA, Ana Paula Fernanda, Andrade, Fernanda Atanaena Gonçalves, Fernandes. "Dois anos de monitoramento dos atropelamentos de mamíferos na rodovia PA-458, Bragança, Pará" In Boletim do Museu Paraense Emilio Goeldi Ciências Naturais. Vol. 1, n. 3, Belém, 2006.

PEREIRA, Luci Cajueiro Carneiro. "Morfologia da praia de Ajuruteua-Pa (Brasil), durante uma maré equinocial de sizígia" In Anais do II Congresso sobre Planejamento e Gestão das Zonas Costeiras dos Países de Expressão Portuguesa, 2001.

QUEIROZ, Helder L. e PERALTA, Nelissa. Reserva de desenvolvimento sustentável: manejo integrado dos recursos naturais e gestão participativa. In I. Garay e B.K. Becker (orgs.). Dimensões humanas da biodiversidade. Petrópolis: Editora Vozes, 2006.

RAMALHO, Cristiano Wellington Noberto. A desnecessidade do trabalho entre pescadores artesanais. In : Sociologias, Porto Alegre, ano 17, n. 38, p. 192-220, jan/abril, 2015.

REIS, M. R. R. Na Friadagem do Mangal: organizar e tirar caranguejos nos fins de semana em Braganca (Vila do Acarajó). Dissertação de Mestrado em Ciências Sociais. Universidade Federal do Pará. Belém/Pará, 115 p. 2007.

SAINT-PAUL, Ulrich e SCHNEIDER, Horacio (orgs). Mangrove Dynamics and management in Norht Brazil. Berlin: Springer, 2010.

SIMÕES, M. F. Coletores e Pescadores Ceramistas do Litoral do Salgado (Pará). Nota preliminar: Boletim do Museu Paraense Emílio Goeldi, nova série antropologia, (78), 1981. VANNUCCI, Marta. Os manguezais e nós: uma síntese de percepções. São Paulo: Editora Universidade de São Paulo, 2002.

Recebido em: 30/10/2016. Aprovado em: 02/12/2016. 